\title{
Patient satisfaction to health service delivery and associated factors at negelle arsi general hospital and medical college, oromia regional state, south- east Ethiopia
}

\begin{abstract}
Introduction: Patient satisfaction is patient's judgment of their desires and expectations of health care. It is recognized as an important parameter for assessing the quality of patient care services delivered by healthcare organizations. Therefore, it reflects the gap between the expected services and the experience of the service.

Objective: To assess patient satisfaction toward Health service deliveries and factors associated with satisfaction at Negele Arsi General Hospital and Medical College, Negelle, Ethiopia, 2018.

Method: Institutional based cross-sectional study design was conducted. All patients greater than 18 years old visited Health service deliveries at NegeleArsi General Hospital and Medical College during study period were included. Critically ill patients were excluded. All items in the structured questionnaire were scored on five-point Likert scale. Data was collected by one nurse diploma holder. Data was entered in to SPSS version 20 computer program by investigator for analysis. Most of the responses were analyzed descriptively with simple frequency distribution as a measure of central tendency and percentages.

Results: The proportion of the patients who were satisfied in health care services rendered at Negele Arsi General Hospital and Medical College was $90.8 \%$ and among the respondents $2.0 \%$ were dissatisfied and $7.2 \%$ were neutral. Majority of the patients were satisfied with the Pharmacy services $(95.7 \%)$. Similarly, 84(93.3\%) of the respondents were satisfied with the services rendered by Physicians, Midwifery and Nurses. On the contrary, the proportions of low satisfied respondents $(85.0 \%)$ were with the Laboratory services.
\end{abstract}

Conclusion and recommendation: The proportion of the patients who were satisfied was relatively high. However, payment for the service, and long waiting time for laboratory result were found to be the major causes of dissatisfaction. Therefore, the Hospital management should identify these departments and plan for a better service delivery.

Keywords: satisfaction, patients, hospital, negele arsi
Volume 4 Issue 6 - 2020

\author{
Ashebir Nigussie Yirgu,' Moges Daba, ${ }^{2}$ Segni \\ Bekele Wakwaya ${ }^{3}$ \\ 1,2Negelle Arsi General Hospital and Medical College, \\ Department of Anesthesia, Negelle Arsi, Ethiopia \\ ${ }^{3}$ Negelle Arsi General Hospital and Medical College, \\ Department of Surgery, Negelle Arsi, Ethiopia
}

\author{
Correspondence: Ashebir Nigussie Yirgu, Negelle Ars \\ General Hospital and Medical College, Department of \\ Anesthesia, Negelle Arsi, Ethiopia, \\ Tel +25196728682I/+251962022082, \\ Email ashebirnigussie@gmail.com
}

Received: November 06, 2020 | Published: November 16, 2020
Abbreviation: NAGHMC, negelle arsi general hospital and medical college

\section{Introduction}

Concerning to client, satisfaction is the level of happiness that clients experience having used a service. Therefore, it reflects the gap between the expected service and the experience of the service, from the client's opinion. ${ }^{1}$ The Ethiopian Federal Ministry of Health $(\mathrm{FMOH})$ has running a sector wide reform effort aimed at significantly improving the quality and the availability of the service at all levels of the country through implementing hospital reform guideline. One of the components of this guideline is improving service quality, achieved by caring out of survey on patient satisfaction on the regular bases. ${ }^{2}$ Patient satisfaction surveys in 2011, surveyed 32 different large tertiary hospitals in the USA to identify the relationship of nursing care, physician care and physical environment to the overall patient satisfaction and the results showed that all care were statistically significant and positively related to overall satisfaction; however, nursing care was the most critical to increase overall patient satisfaction. The researchers also found that the courtesy and respect of healthcare providers impact more on patient satisfaction while communication and explanation are the second most important aspect. ${ }^{3}$ In Ethiopia study findings concerning level of patient satisfaction in different types of health facilities and hospitals were different. A study on the quality of hospital services in eastern Ethiopia based on patient's perspective indicated that $46 \%$ of patients were not satisfied while the study conducted at Jimma Specialized hospital indicated overall client satisfaction of $77 \%$. Studies performed in Gondar and Jimma hospitals on outpatient services satisfaction showed $22 \%$ and $57 \%$ satisfaction level respectively. ${ }^{4}$ Findings in Hawassa University Teaching Hospital displayed as $80.1 \%$ of patients were pleased with the outpatient health service expected such as stay length for the care, existence of good conversation with service givers, caring of patient privacy, good situations to ask questions, and ease of use of needed services. ${ }^{5}$ So, the aim of the study done in Negelle Arsi General Hospital and Medical College was to assess the level of patients' satisfaction on health service deliveries in private Hospital. Therefore, it is important for improvement of quality and effectiveness of health care services. 


\section{Methods and materials}

Study settings: Facility based cross-sectional study design was conducted in Negele Arsi General Hospital and Medical College which is located in Oromia regional state in west Arsi Zone, Ethiopia. It is one of the towns of western Arsi zone of Oromia regional state which is located on the way to Shashemene approximately about $21 \mathrm{~km}$ away from Shashemene, capital town of West Arsi zone and $250 \mathrm{~km}$ from capital city of Ethiopia, Addis Ababa. The private hospital was established in 2010 G.C when it was the only hospital in Negele town. The facility gives community service, Hospital service and teaching purpose. Currently, it is providing for cold case and emergency services.

Source population: All clients attended Health service deliveries at Negele Arsi General Hospital and Medical College, Negelle Arsi, Ethiopia, 2018.

Study population: All clients attended Health service deliveries from January 01- 15 at Negele Arsi General Hospital and Medical College, Negelle Arsi, Ethiopia, 2018.

Inclusion criteria: All patients greater than 18 years old.

Exclusion criteria: Critically ill patients and patients who had mental problems.

Sampling technique: Includes all patients visiting Outpatient department, Inpatient department, Emergency department and Maternity department within specified time period.

\section{Data collection tools and procedures}

Face to face interviewed method was used. Items were valued using five-point Likert scales: (1=very dissatisfied, $2=$ dissatisfied, $3=$ neither satisfied nor dissatisfied, $4=$ satisfied and $5=$ very satisfied). Respondents' answers to the questions valued with grades 4 and 5 were measured to indicate satisfied state, respondents' answers "neither satisfied nor dissatisfied" (grade 3) were measured neutral responses, and respondents' answers assessed with grades 1 and 2 were expressed dissatisfaction with the examined variables. Clients who completed their visit is interviewed as they were leaving the OPD departments, Emergency department and exit interview to inpatient clients on their discharge date.

\section{Data quality assurance}

After pretest was done, data collector and supervisor were trained on each item included in the study. During collection of data, regular supervision and follow up was made. After data was composed and checked for completeness, consistency and accuracy it was arranged categorized and summarized.

\section{Data processing and analysis}

The data was cleaned, edited and checked for completeness. Data was entered in to SPSS version 20 computer program by investigator for processing and analysis. Descriptively, findings were reported in data, tables and figures. Then, the data were analyzed using appropriate descriptive tests.

\section{Ethical clearance}

Permission to conduct and confirmation was obtained from ethical review committee of Negele Arsi General Hospital and Medical College. Each study participant was asked to participate voluntarily, after they had been informed about the objective of the study. If agreed to participate, informed consent was obtained. Confidentiality of the participants' information was kept throughout the research processes.

\section{Results}

\section{Socio-demographic characteristics}

A total of 100 patients were interviewed within specified time period. Most proportions of respondents 36(36.0\%) were between 3340 year old followed by $28(28.0 \%)$ which belongs to the age group of $\geq 41$ years. Less than half, $44(44.0 \%)$ of the respondents were Farmer, whereas $53 \%$ where living in Urban. Majority of the respondents, $84 \%$ was married and more than half, $53 \%$ of them were female (Table 1).

Table I Socio-demographic characteristics of patients who took health care services in Negelle Arsi General Hospital and Medical College, Negelle, Ethiopia, $2018(n=100)$

\begin{tabular}{llll}
\hline Variable & Category & Frequency $(\mathbf{n}=100)$ & Percent (\%) \\
\hline \multirow{3}{*}{ Age } & $18-25$ & 11 & 11 \\
& $26-32$ & 25 & 25 \\
Sex & $33-40$ & 36 & 36 \\
& $\geq 41$ & 28 & 28 \\
Marital status & Male & 47 & 47 \\
& Female & 53 & 53 \\
& Single & 11 & 11 \\
& Married & 84 & 84 \\
& Widowed & 4 & 4 \\
Residence & Divorced & 1 & 1 \\
& Urban & 53 & 53 \\
& Rural & 47 & 47 \\
& Government employer & 10 & 18 \\
\hline
\end{tabular}




\begin{tabular}{llll} 
Table Continued... & & \\
\hline Variable & Category & Frequency $(\mathbf{n}=100)$ & Percent (\%) \\
\hline Occupation & House wife & 15 & 15 \\
& Farmer & 44 & 44 \\
& Private employer & 8 & 8 \\
& Others & 5 & 5 \\
\hline
\end{tabular}

\section{Client's satisfaction toward health care services}

Overall proportion of respondents who were satisfied was $90.8 \%$ and $2.0 \%$ was not satisfied and the rest was neutral by services rendered in all departments in the Hospital. Satisfaction level by given service in Pharmacy, Other health Professionals and Laboratory personnel were 95.7, 93.3 and 85.0, respectively. Almost all, $95.0 \%$ of the respondents reported toilets and bathrooms were clean during all times of his/her encounter. Of the respondents, $87.0 \%$ of them satisfied with acceptable waiting time to get evaluated especially in OPD and Emergency. 97.2\% confirmed as they had a good communication and collaboration with health care givers.

Concerning ward services, from respondents, similarly, $85.0 \%$ were satisfied with pain management, adequate supply of hospital gowns and pajamas and felt as served equally irrespective of his/ her status including religion, gender, age, economic status, social status, place of living, etc. The lowest satisfaction level, $49.0 \%$ was in payment for the service.

\section{Patients' satisfaction with laboratory services}

Almost all of the respondents (97\%) were satisfied concerning workers.73\% of them got satisfaction in adequate information was provided regarding the process of test and $11 \%$ of them were dissatisfied (Figure 1)

\section{Proportion of patient satisfaction on payment for different services}

This figure showed combinations of payment for Registration, drugs, procedures and laboratory investigations. Generally, 49\% was satisfied with payments (Figure 2).

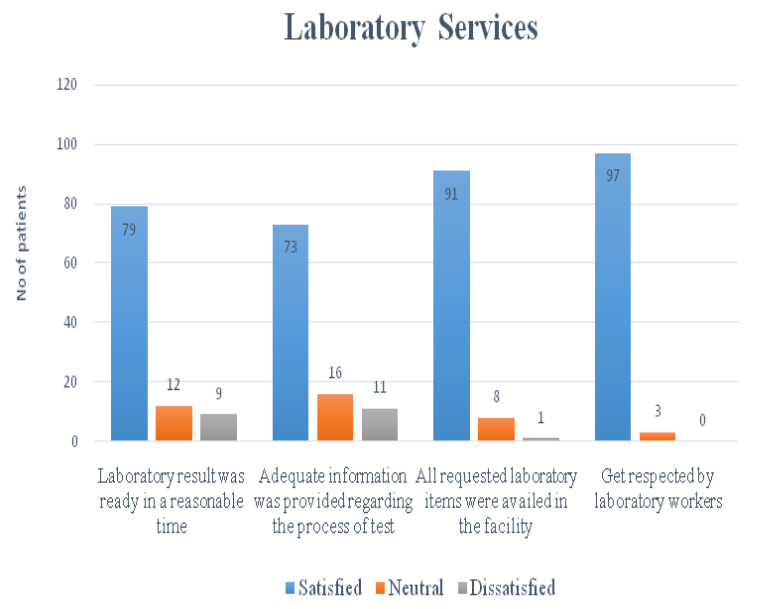

Figure I Proportion of patients who took Laboratory services in Negelle Arsi General Hospital and Medical College, Negelle, Ethiopia, 2018.

\section{The Payment for the Service}

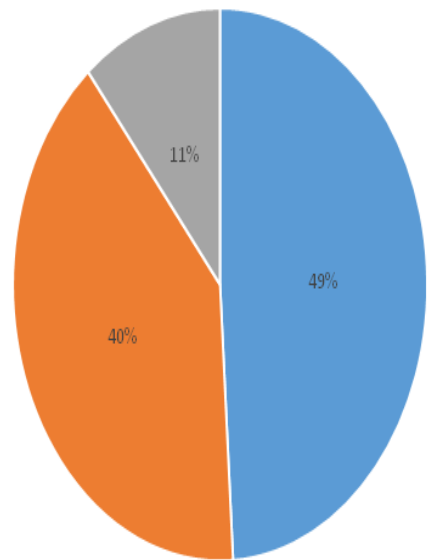




\section{Discussion}

This study revealed that the overall patients' satisfaction with the health care services they received was $90.8 \%$. This finding is lower than study conducted in Nigeria and Kuwait in which the patient satisfaction was $94.2 \%$ and $99.6 \%$ respectively [6]. The difference could be due to subjective nature of satisfaction, and with better quality of health care system than Ethiopia. The overall state of satisfaction (90.8\%) of the respondent in this study was higher when compared to other studies. The study at Jimma specialized (2010) and Tikur Anbassa (2012) hospital indicates satisfaction rate of $77.0 \%$ and $90.1 \%$ respectively. ${ }^{4}$ The reason may be due to changes in the service delivery process and health workers may be highly motivated. The overall proportion of patients who were satisfied with acceptable waiting time to get evaluated especially in OPD in this study was $87.0 \%$. This percentage is lower compared to other studies done at Sassoon General Hospital Pune on patient's satisfaction revealed that $91 \%$ of patient said that OPD timings were convenient. ${ }^{7}$ The difference may be due to personal nature of satisfaction and differences in period. Relating to marital status this study displayed that $84.0 \%$ married patient was satisfied than $11.0 \%$ of single, $4.0 \%$ of widowed and $1.0 \%$ of divorced patients'. This is similar with finding in Turkey that married patients' satisfaction levels are more than those of widowed and divorced patients. ${ }^{8}$ This might be due to more than half of the patient was married. In our study, patient's satisfaction with cleanliness of toilets during all times of their encounter was $95.0 \%$. In opposite, study conducted on patients admitted in a tertiary care hospital in Nagpur, India ${ }^{9}$ during 2008 indicated that dissatisfaction was found to be more with poor cleanliness of toilets $(44.0 \%)$. This may be due to the availability of water supply always in our hospital and the strength of our cleaners. Also, the overall satisfaction level of laboratory service was $85.0 \%$. This result is inconsistent with the report $(85.5 \%)$ of similar study conducted in Addis Ababa, Ethiopia. ${ }^{10}$ However, this finding is higher than the report $(60.4 \%)$ of other Ethiopian study from Nekemte Referral Hospital. ${ }^{10}$ In this study, neatness of the ward was one of the extensively allowed items by our clients (100.0\%) as the highest level of satisfaction, which is higher when compared to a study in Dar Es Salaam, Tanzania which was $88.5 \% .{ }^{11}$ Our study displayed that the highest $19.5 \%$ rate of dissatisfaction was due to the food service which could be due to the fact that most patients were kept in their bed and they can't get food from hospital cafeteria during night. The study conducted in our hospital, (99\%) of the respondent was satisfied by accessibility of different indicators found in the hospital which showed the direction. In contrary, at Bahirdar Felege Hiwot Referral Hospital, on private wing patients, only $29.2 \%$ were satisfied to the accessibility of different indicators which showed direction in the hospital. ${ }^{12}$

Limitation: - Study participants' number was low. We didn't use sample size determination. The researcher doesn't assess the quality of services by type.

\section{Conclusion and recommendations}

Conclusion: The overall proportion of respondents satisfied with services given was $90.8 \%$. Almost half, $49.0 \%$ were dissatisfied with the payments for the service. The lowest level of patient satisfaction $(79.0 \%)$ was recorded in laboratory services specifically in relation to waiting time for the result.

Recommendation: The overall proportions of satisfaction of the respondents were high. Payment for the service, inadequate pain management, unable to identify the health care workers, Lack of information and waiting time for the laboratory result, inadequate supply of hospital gowns and pajamas were the area which influences satisfaction level. Therefore, recommend that the hospital administration may need to take the necessary action on the gaps identified.

\section{Authors' contributions}

AN has contributed to conducting case, drafted manuscript, review of literature, revision of manuscript; AS and SB has contributed to conducting case, drafted manuscript, review of literature and revision of manuscript. All authors read and approve the final manuscript.

\section{Acknowledgments}

Our heartfelt thanks go to all study participants and data collectors who participated in the study. I wish to acknowledge my debts to Dr. Fikadu Assefa Jiru for his suggestions and valuable advice.

\section{Conflicts of interest}

No conflict of interest between authors.

\section{References}

1. Sagaro GG, Yalew AW, Koyira MM. Patients' satisfaction and associated factors among outpatient Department at Wolaita Sodo University Teaching Hospital, Southern Ethiopia: a cross sectional study. Sci J Clin Med. 2015;4(5):109-116.

2. Blass AP, da Costa SEG, de Lima EP, et al. Measuring environmental performance in hospitals: A practical approach. Journal of cleaner production. 2017;142:279-289.

3. Al-Abri R, Al-Balushi A. Patient satisfaction survey as a tool towards quality improvement.Oman medical journal. 2014;29(1):3.

4. Tateke T, Woldie M, Ololo S. Determinants of patient satisfaction with outpatient health services at public and private hospitals in Addis Ababa, Ethiopia. African Journal of Primary Health Care \& Family Medicine. 2012;4(1):384.

5. Mulisa T, Tessema F, Merga H. Patients's satisfaction towards radiological service and associated factors in Hawassa University Teaching and referral hospital, Southern Ethiopia. BMC health services research. 2017;17(1):441

6. Nabbuye-Sekandi J, Makumbi FE, Kasangaki A, et al. Patient satisfaction with services in outpatient clinics at Mulago hospital, Uganda. International Journal for Quality in Health Care. 2011;23(5(:516-523.

7. Mala FA, Lone MA, Lone FA, et al. Ethno-medicinal survey of Kajinaag range of Kashmir Himalaya, India. International Journal of Pharma and Bio Sciences. 2012;3(2).

8. Özlü ZK, Uzun Ö. Evaluation of satisfaction with nursing care of patients hospitalaized in surgical clinics of different hospitals. International Journal of Caring Sciences. 2015;8(1):19-24.

9. Ababa A. Assessment of inpatients 'satisfaction on quality of care and associated factors at zewditu memorial hospital, addis ababa. school of public health, college of health sciences, addis ababa university. 2015.

10. Tadele G, Ejeta E, Desalegn M, et al. Patients Satisfaction on Clinical Laboratory Services at Nekemte Referral Hospital, Oromia, Ethiopia. Food Science and Quality Management. 2014;30:25-30.

11. Muhondwa E, Leshabari M, Mwangu M, et al. Patient satisfaction at the Muhimbili national hospital in Dar Es Salaam, Tanzania. East Afr J Public Health. 2008;5(2):67-73.

12. Ambelie YA, Demssie AF, Gebregziabher MG. Patients' satisfaction and associated factors among private wing patients at Bahirdar Felege Hiwot Referral Hospital, North West Ethiopia. Sci J Public Health. 2014;2(5):417-423. 